\title{
Pengabdian dalam Upaya Pencapaian Kondisi Permukiman, Sarana, dan Prasarana Sehat Dalam Mewujudkan Kabupaten Banyuwangi Sehat di Tahun 2021
}

\author{
Nur Anim Jauhariyah¹, Soekardjo² ${ }^{2}$ Pipit Hariyono ${ }^{3}$ \\ ${ }^{1}$ IAI Darussalam Blokagung Banyuwangi, 2,3STIKES Banyuwangi \\ Email : ${ }^{1}$ animjauhariyah@gmail.com
}

\begin{abstract}
This service in efforts to achieve healthy housing conditions, facilities and infrastructure in realizing a Healthy Banyuwangi Regency is carried out as an effort to maintain environmental comfort and health, including reforestation activities by planting trees and protecting rivers from pollution. The data shows that the number of trees planted from 2013 to 2020 is 7,774,132. Although the Covid-19 pandemic still haunts people's lives, activities in an effort to improve the quality of proper air and water continue to carry out health protocols.
\end{abstract}

Keywords: Community Service, Healthy Facilities and Infrastructure Settlement, Banyuwangi Regency

\section{Pendahuluan}

Pemerintah Kabuapaten Banyuwangi terus bersinergi dengan masyarakat dalam menjaga predikat Kabupaten Sehat. Kabupaten/Kota Sehat merupakan suatu kondisi kabupaten/kota yang bersih, nyaman, aman dan sehat untuk dihuni penduduk, yang dicapai melalui terselenggaranya penerapan beberapa tatanan dan kegiatan yang terintegrasi yang disepakati masyarakat dan pemerintah daerah. ${ }^{1}$

Kabupaten sehat mewujudkan kawasan Sehat yang merupakan suatu kondisi wilayah yang bersih, nyaman, aman dan sehat bagi pekerja dan masyarakat, melalui peningkatan suatu kawasan potensial dengan kegiatan

1 Peraturan Bersama Menteri Dalam Negeri Dan Menteri Kesehatan Nomor 34 tahun 2005 nomor: 1138/MENKES/PB/VIII/2005 Tentang Penyelenggaraan Kabupaten/Kota Sehat Dengan Rahmat Tuhan Yang Maha Esa Menteri Dalam Negeri Dan Menteri Kesehatan.

Pengabdian dalam Upaya Pencapaian Kondisi Permukiman, Sarana, dan Prasarana Sehat Dalam Mewujudkan Kabupaten Banyuwangi Sehat di Tahun 2021

Nur Anim Jauhariyah, Soekardjo, Pipit Hariyono 
yang terintegrasi yang disepakati masyarakat, kelompok usaha dan pemerintah daerah. Penghargaan yang diberikan oleh pemerintah untuk penyelenggaran kabupaten/kota sehat disebut dengan Swasti Saba yang diberikan oleh pemerintah kepada masyarakat melalui Bupati/Walikota atas keberhasilan dalam menyelenggarakan Kabupaten/Kota Sehat.

Kabupaten Banyuwangi telah melaksanakan Kabupaten Sehat dimulai pada tahun 2011 dengan memperoleh penghargaan pertama yaitu Swasti Saba Padapa pada Tahun 2015, Wiwerda Tahun 2017, dan penghargaan tertinggi Wistara pada Tahun 2019. Pada Tahun 2021 Kabupaten Banyuwangi sedang berjuang dalam mendapatkan penghargaan Swasti Saba Wistara untuk kedua kalinya. Penyelenggaraan penilaian/ verifikasi dilaksanakan pada tahun genap untuk tingkat provinsi dan tahun ganjil untuk tingkat nasional.

Kabupaten Banyuwangi Tahun 2021 menyetorkan dokumen dengan komposisi 6 tatanan di Kabupaten Banyuwangi. Salah satu tatanan dalam mencapai Kabupaten Sehat adalah tatanan permukiman, sarana dan prasarana sehat. Dalam pengabdian ini upaya yang dilakukan dalam mencapai kondisi udara bersih dalam mewujudkan kenyamanan dan kesehatan lingkungan maka berbagai upaya dilaksanakan diantaranya adalah festival sedekah oksigen melalui penanaman pohon dan menjaga kondisi sungai dari kegiatan yang dapat menyebabkan pencemaran air, sehingga kondisi udara dan air yang bersih dapat menambah indeks kesehatan masyarakat.

\section{Metode}

Pemberdayaan ini menggunakan pendekatan Participatory Action Research $(P A R)^{2}$ Pada uraian ini akan dipaparkan beberapa aksi yang dilakukan

2 INAYAH, Nurul et al. Pemberdayaan Masyarakat Dalam Usaha Peningkatan Pendapatan Keluarga Sejahtera (UPKKS). LOYALITAS, Jurnal Pengabdian Kepada Pengabdian dalam Upaya Pencapaian Kondisi Permukiman, Sarana, dan Prasarana Sehat Dalam Mewujudkan Kabupaten Banyuwangi Sehat di Tahun 2021 
oleh tim pendamping sebagai langkah awal untuk mewujudkan kondisi permukiman sarana dan prasarana sehat dengan kegiatan penanaman pohon di beberapa titik di Kabupaten Banyuwangi. Kegiatan ini berlangsung pada Maret 2021 walaupun di masa pandemi, kegiatan tetap haru saktif dengan tetap menjalankan protokol kesehatan. Kegiatan dilaksanakan dengan bersinergi dengan kegiatan pemerintah Kabupaten Banyuwangi dengan melibatkan forum, stakehlders, masyarakat, dan dinas terkait.

\section{Hasil dan Diskusi}

Walaupun masih dalam kondisi pandemi, namun kegiatan harus tetap berjalan. Terlebih lagi dalam upaya menjaga permukinam, sarana, dan prasarana tetap sehat walaupun dimasa pandemi yag masih menghantui kondisi kehidupan di masyarakat.

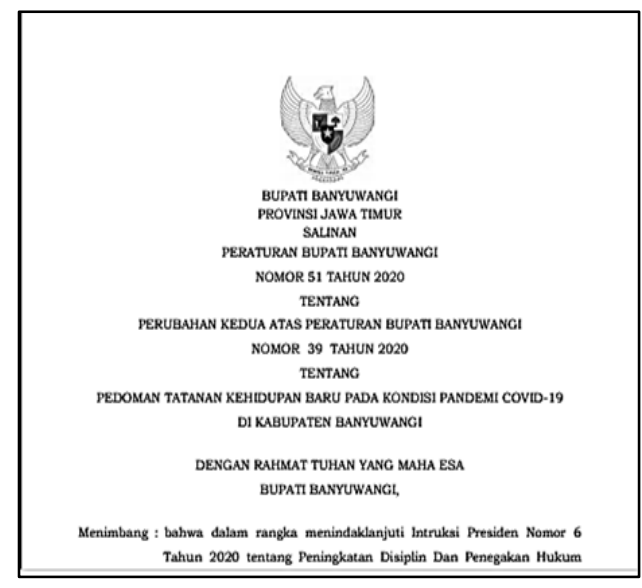

\section{Gambar 1. Regulasi yang Mendukung Tatanan Kehidupan Baru di Masa Pandemi Covid 19}

Dimasa pandemi ini Bupati membuat produk hukum terkait pedoman tatanan kehidupan baru pada masa pandemi covid 19 sebagaimana tertuang

Masyarakat, [S.l.], v. 2, n. 1, p. 112-123, may 2019. ISSN 2621-4687. Available at: <http://ejournal.iaida.ac.id/index.php/loyal/article/view/409>. Date accessed: $15 \mathrm{dec}$. 2020.

Pengabdian dalam Upaya Pencapaian Kondisi Permukiman, Sarana, dan Prasarana Sehat Dalam Mewujudkan Kabupaten Banyuwangi Sehat di Tahun 2021

Nur Anim Jauhariyah, Soekardjo, Pipit Hariyono 
dalam Peraturan Bupati Banyuwangi Nomor 51 Tahun 2020 Tentang Perubahan Kedua Atas Peraturan Bupati Banyuwangi Nomor 39 Tahun 2020 Tentang Pedoman Tatanan Kehidupan Baru Pada Kondisi Pandemi Covid-19 Di Kabupaten Banyuwangi. Kegiatan pencegahan penularan covid 19 seperti pembagian masker, penyemprotan disinfektan, kegiatan sosialisasi melalui media sosial WA, Instagram, Facebook.

Gerakan Menanam Pohon yang dilakukan secara sukarela; Sesuai dengan pasal 6 Peraturan Bupati No 46 Tahun 2013 bahwa tanaman yang dianjurkan untuk di tanam adalah jenis tanaman trembesi sebesar 70\% dan tanaman Holtikultura atau buah-buahan sebesar 30\%.

Tabel 1. Data Penanaman Pohon

\begin{tabular}{|l|c|c|}
\hline No & Tahun Penanaman & Jumlah Pohon \\
\hline 1 & Penanaman 2013 & 1.169 .000 \\
\hline 2 & Penanaman 2014 & 910.000 \\
\hline 3 & Penanaman 2015 & 5.259 .223 \\
\hline 4 & Penanaman 2016 & 68.090 \\
\hline 5 & Penanaman 2017 & 28.850 \\
\hline 6 & Penanaman 2018 & 255.453 \\
\hline 7 & Penanaman 2019 & 83.516 \\
\hline 8 & Penanaman 2020 & $\mathbf{7 . 8 1 6 . 4 9 4}$ \\
\hline & Jumlah & $\mathbf{2 0 2 1 6}$ \\
\hline
\end{tabular}

\section{Sumber: DLH Kabupaten Banyuwangi, 2021}

Peraturan Bupati Banyuwangi No 46 Tahun 2013 tentang Shodaqoh Oksigen adalah diharapkan seluruh warga Banyuwangi secara individuuntuk gemar menanam dan pada saatnya nanti, menanam pohon menjadi bagian budaya untuk masyarakat Banyuwangi. Penduduk Kabupaten Banyuwangi saat ini \pm 2 Juta jiwa, untuk itu apabila setiap penduduk menanam 1 pohon 
maka tanaman yang ditanam di Kabupaten Banyuwangi minimal sebanyak 2 juta tanaman; melalui Peraturan Bupati tentang Shodaqoh Oksigen ini diharapkan dapat membangun kesadaran seluruh masyarakat Kabupaten Banyuwangi untuk mau dan mampu melakukan kegiatan menanam pohon secara mandiri dan lestari.
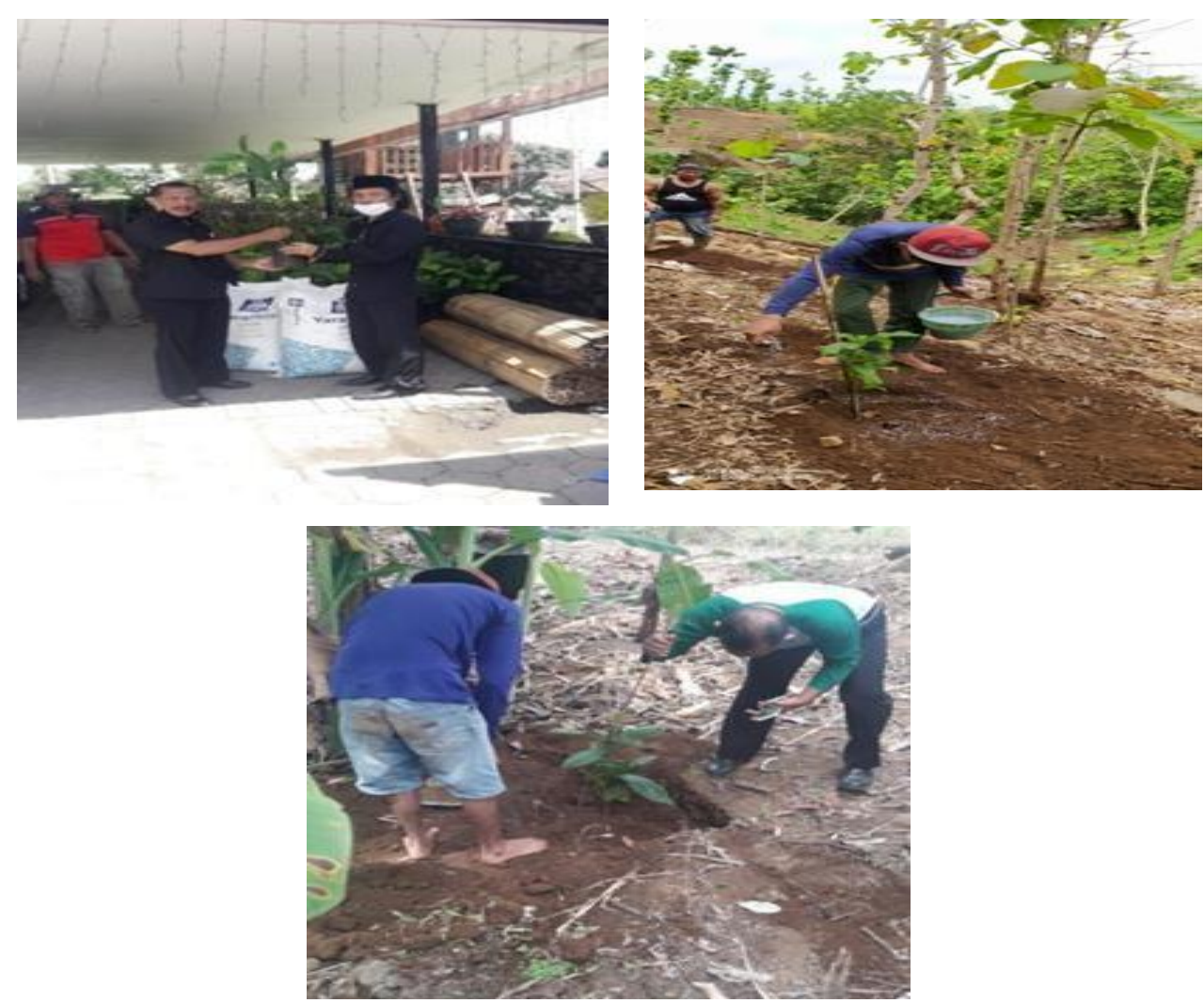

\section{Gambar 1. Penyerahan Bibit dan Proses Penghijauan di Kabupaten Banyuwangi (Sumber: DLH Kabupaten Banyuwangi, 2021)}

Penghijauan dilaksanakan melalui penanaman pohon di sekitar sumber mata air, agroforestri, rehabilitasi lahan kritis maupun melalui kegiatan bersama stakeholder. Adapun total penghijauan yang telah dilaksanakan pada tahun 2019 - 2020 adalah 87.653 pohon. Kegiatan penghijauan dilaksanakan di sumber mata air, di lahan kritis, dan di sela-sela tanaman yang sudah ada (Agroforestri) guna mendukung kegiatan Shodaqoh Oksigen 
sebagaimana Peraturan Bupati Banyuwangi Nomor 46 Tahun 2013 pada tanggal 17 Desember 2013 adalah kesadaran setiap orang atau badan untuk melakukan amal kebaikan dan kepedulian terhadap ketersediaan oksigen berupa gerakan menanam pohon.
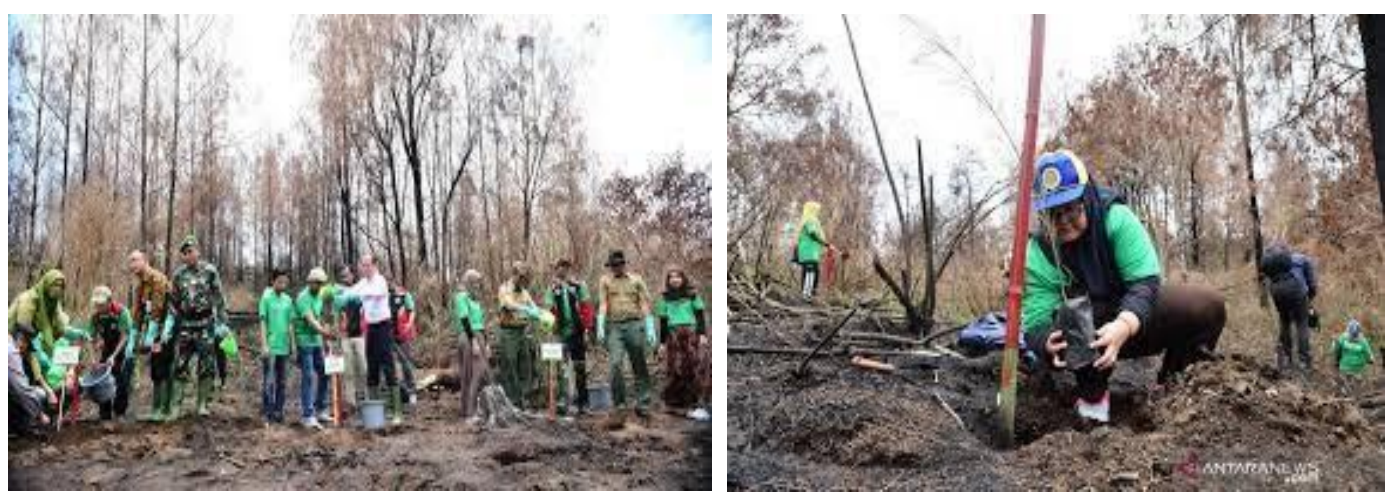

Gambar 2. Kegiatan Penghijauan di Eks Kebakaran Gunung Ijen (Sumber: Dokumentasi Kegiatan, 2021)
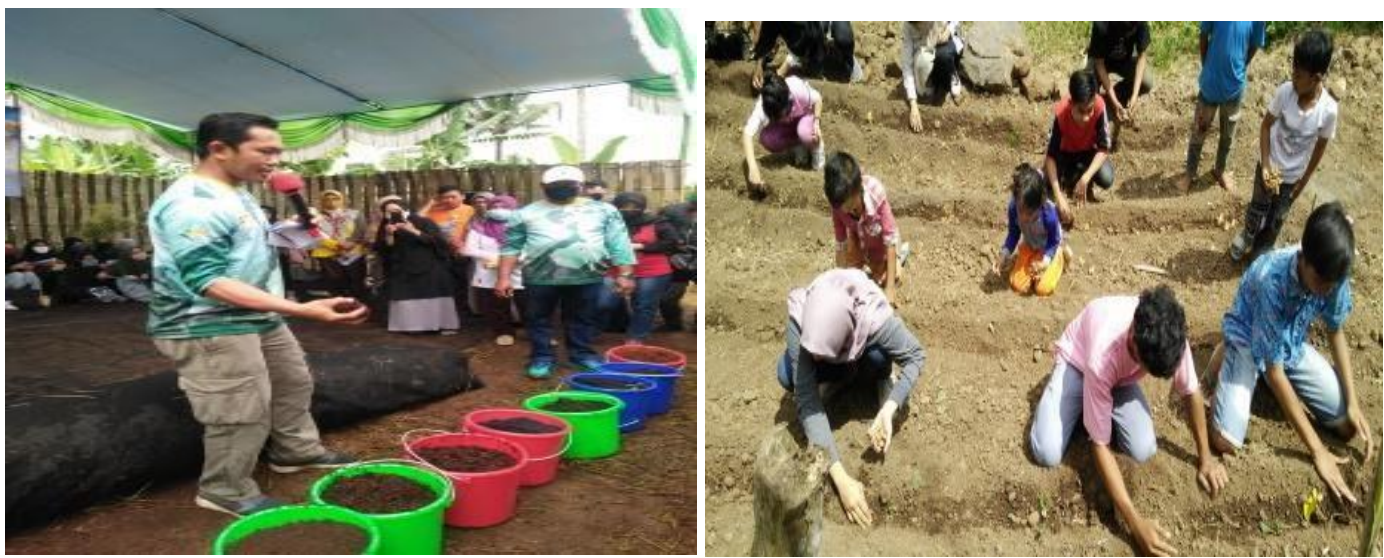

Gambar 3. Pelatihan Kompetensi dukasi Jenis-Jenis Media Tanam Sesuai Fungsinya Dan Edukasi Jenis-Jenis Tanaman TOGA (Sumber: Dokumentasi Kegiatan, 2021)

Tujuan dan manfaat dari kegiatan ini adalah untuk menjaga dan menjamin ketersediaan oksigen untuk keberlangsungan makhluk hidup di bumi. Adapun jumlah pohon yang ditananam sejak tahun 2013 hingga tahun 2020adalah sebanyak 7.774.132. Tahun 2019 kegiatan penanaman dilakukan

Pengabdian dalam Upaya Pencapaian Kondisi Permukiman, Sarana, dan Prasarana Sehat Dalam Mewujudkan Kabupaten Banyuwangi Sehat di Tahun 2021

Nur Anim Jauhariyah, Soekardjo, Pipit Hariyono 
sebanyak 83.516 dan tahun 2020 kerena masa pandemi kegiatan penenaman pohon sebanyak 42.362 pohon.

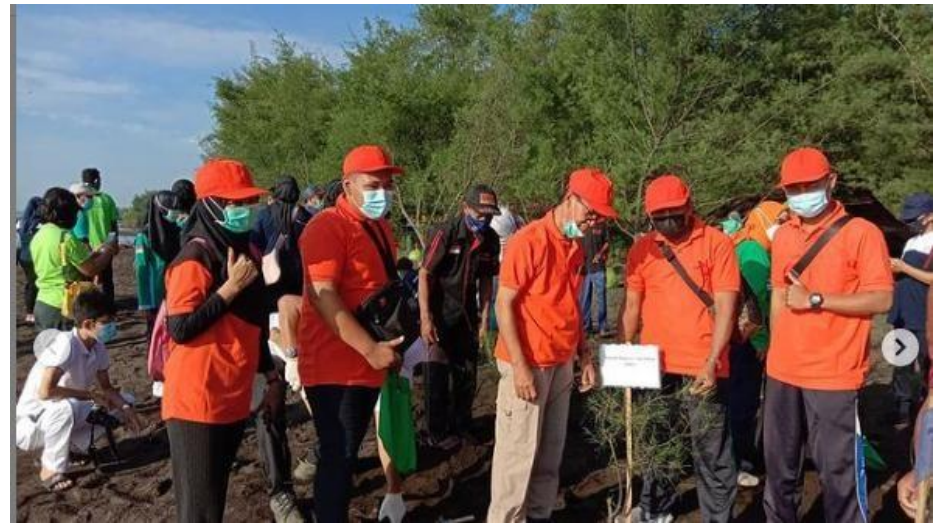

\section{Gambar 4. Pelaksanaan Penanaman Pohon di Pantai (Sumber: Dokumentasi Kegiatan, 2021)}

Kabupaten Banyuwangi menggelar rangkaian Festival Sedekah Oksigen yang rutin dilaksanakan setiap tahun. Acara itu masuk dalam rangkaian Banyuwangi Festival mulai pada Tahun 2018 yang merupakan ajang promosi wisata. Pelaksanaan kampanye wajib tanam pohon bagi masyarakat di Kabupaten Banyuwangi diperingati dengan menggelar rangkaian Festival Sedekah Oksigen yang rutin dilaksanakan setiap tahun. Himbauan untuk menanam pohon dilakukan melalui sosialisasi baik media cetak maupun elektronik. Jumlah desa/kelurahan yang melaksanakan kegiatan wajib tanam pohon diKabupaten Banyuwangi antara 60-80\%.

Kondisi pandemi menyebabkan penurunan pada kunjungan wisata karena ada sistem buka tutup tempat wisata. Pertumbuhan kunjungan wisatawan menggambarkan seberapa besar prosentase dari wisatawan yang datang ke Kabupaten Banyuwangi untuk menginap atau mengunjungi destinasi wisata di Kabupaten Banyuwangi. ${ }^{3}$

3 JAUHARIYAH, Nur Anim; HABIBULLOH, Habibulloh; YAZID, Azy Athoillah. POTRET PERTUMBUHAN KUNJUNGAN WISATAWAN DALAM PERSPEKTIF ISLAM DI

Pengabdian dalam Upaya Pencapaian Kondisi Permukiman, Sarana, dan Prasarana Sehat Dalam Mewujudkan Kabupaten Banyuwangi Sehat di Tahun 2021

Nur Anim Jauhariyah, Soekardjo, Pipit Hariyono 
Selain itu, dalam rangka penyehatan lingkungan permukiman yang berkelanjutan, dan peningkatan derajat kesehatan masyarakat Indonesia sehingga masyarakat dapat menjadi lebih produktif perlu dilakukan pengembangan sistem pengelolaan air limbah permukiman yang ramah lingkungan. Pemerintah Kabupaten Banyuwangi telah memiliki Peraturan Daerah Kabupaten Banyuwangi Nomor 3 Tahun 2011. Tentang Pengendalian Pencemaran Air sehingga tidak hanya kesehatan udara saja yang dijaga, kesehatan sungai juga harus selalu dijaga keberlangsungannya

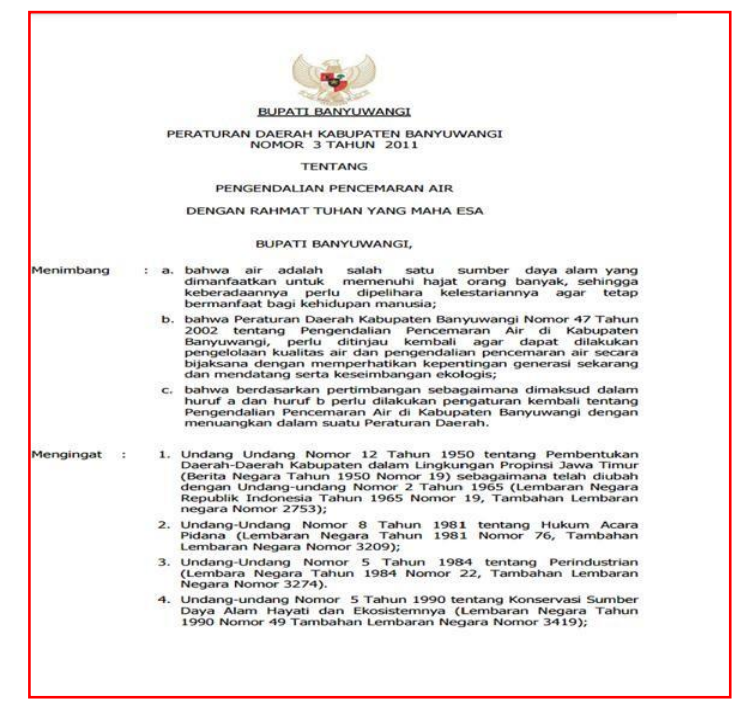

\section{Gambar 5.Perda Tentang Pengendalian Pencemaran Air (Sumber: JDIH Kabupaten Banyuwangi, 2021)}

\section{Simpulan}

Dokumen Verifikasi Penyelenggaraan Kabupaten/Kota Sehat Tahun 2020 di Kabupaten Banyuwangi yang merupakan salah satu cara untuk mewujudkan Banyuwangi yang bersih, nyaman, aman dan sehat dihuni

KABUPATEN BANYUWANGI. Jurnal Ekonomi Syariah Darussalam, [S.I.], v. 2, n. 1, p. 86-99, feb. 2021. ISSN 2745-8407. Available at: <https://ejournal.iaida.ac.id/index.php/IESDar/article/view/883>.

Pengabdian dalam Upaya Pencapaian Kondisi Permukiman, Sarana, dan Prasarana Sehat Dalam Mewujudkan Kabupaten Banyuwangi Sehat di Tahun 2021 
penduduk, yang dicapai melalui terselenggaranya penerapan beberapa tatanan diantaranya upaya dalam mewujudkan kondisi permukiman, sarana, dan prasarana sehat dengan menyelenggarakan kegiatan yang terintegrasi dan bersinergi antara kegiatan masyarakat dengan Pemerintah Daerah Kabupaten Banyuwangi yang telah dilaksanakan semua komponen masyarakat baik sektor pemerintah, swasta, dan masyarakat seperti kegiatan penghijauan dengan menanam pohon untuk menjaga udara bersih dan kegiatan menjaga sungai dari pencemaran.

\section{Referensi}

BPS. 2021. Kabupaten Banyuwangi Dalam Angka 2021. BPS Kabupaten Banyuwangi.

Dinas Lingkungan Hidup Kabupaten Banyuwangi. 2021. Dokumentasi Kegiatan Tahun 2019-2020. DLH.

Forum Banyuwangi Sehat. 2021. Dokumen Verifikasi Nasional 2021. Banyuwangi, FBS.

INAYAH, Nurul et al. Pemberdayaan Masyarakat Dalam Usaha Peningkatan Pendapatan Keluarga Sejahtera (UPKKS). LOYALITAS, Jurnal Pengabdian Kepada Masyarakat, [S.l.], v. 2, n. 1, p. 112-123, may 2019. ISSN 2621-4687. Available at: <http://ejournal.iaida.ac.id/index.php/loyal/article/view/409>. Date accessed: 15 April 2021.

JAUHARIYAH, Nur Anim; HABIBULLOH, Habibulloh; YAZID, Azy Athoillah. POTRET PERTUMBUHAN KUNJUNGAN WISATAWAN DALAM PERSPEKTIF ISLAM DI KABUPATEN BANYUWANGI. Jurnal Ekonomi Syariah Darussalam, [S.I.], v. 2, n. 1, p. 86-99, feb. 2021. ISSN 27458407. Available at: <https://ejournal.iaida.ac.id/index.php/IESDar/article/view/883>.

Date accessed: 15 April 2021.

Peraturan Bersama Menteri Dalam Negeri Dan Menteri Kesehatan Nomor 34 tahun 2005 nomor: 1138/MENKES/PB/VIII/2005 Tentang Penyelenggaraan Kabupaten/Kota Sehat Dengan Rahmat Tuhan Yang Maha Esa Menteri Dalam Negeri Dan Menteri Kesehatan. 